\title{
Correction to: Seismic performance of full-scale RC columns containing high proportion recycled aggregate
}

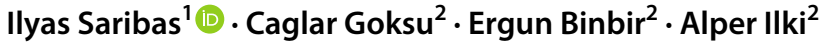

Published online: 19 September 2019

(c) Springer Nature B.V. 2019

\section{Correction to: Bulletin of Earthquake Engineering https://doi.org/10.1007/s10518-019-00687-0}

This erratum is published due to vendor overlooked corrections related to axis of two figures 9 and 13 denoted as $\mathrm{m}$ instead of $\mathrm{mm}$ and needs to be updated.

(a) unit of horizontal axis; from $1 / \mathrm{m}$ to $1 / \mathrm{mm}$ in Fig. 9

(b) unit of vertical axis; from $\mathrm{mm} / \mathrm{mm}$ to $1 / \mathrm{mm}$ in Fig. 13.

The original article has been thus corrected with the corrected references and thus updated.
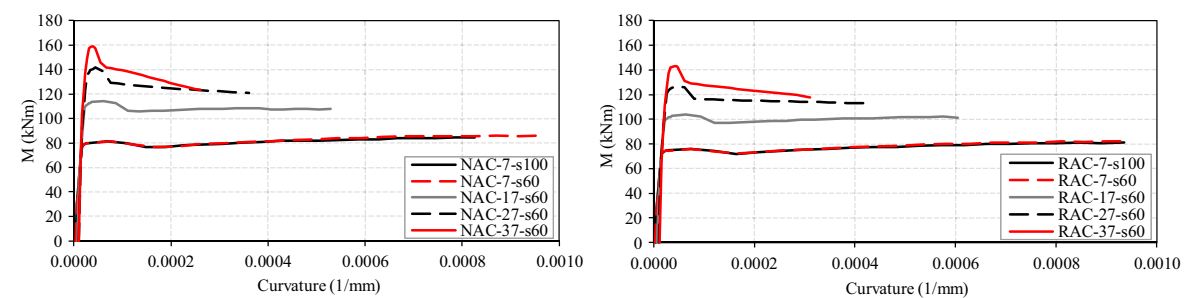

Fig. 9 Theoretically obtained moment-curvature relationships of NAC and RAC columns

The original article can be found online at https://doi.org/10.1007/s10518-019-00687-0.

Ilyas Saribas

ilyassaribas@gmail.com

1 Structural Engineering Division, Engineering Faculty, AAT Science and Technology University, 01250 Saricam, Adana, Turkey

2 Structural and Earthquake Engineering Laboratory, Civil Engineering Faculty, Istanbul Technical University, 34469 Maslak, Istanbul, Turkey 

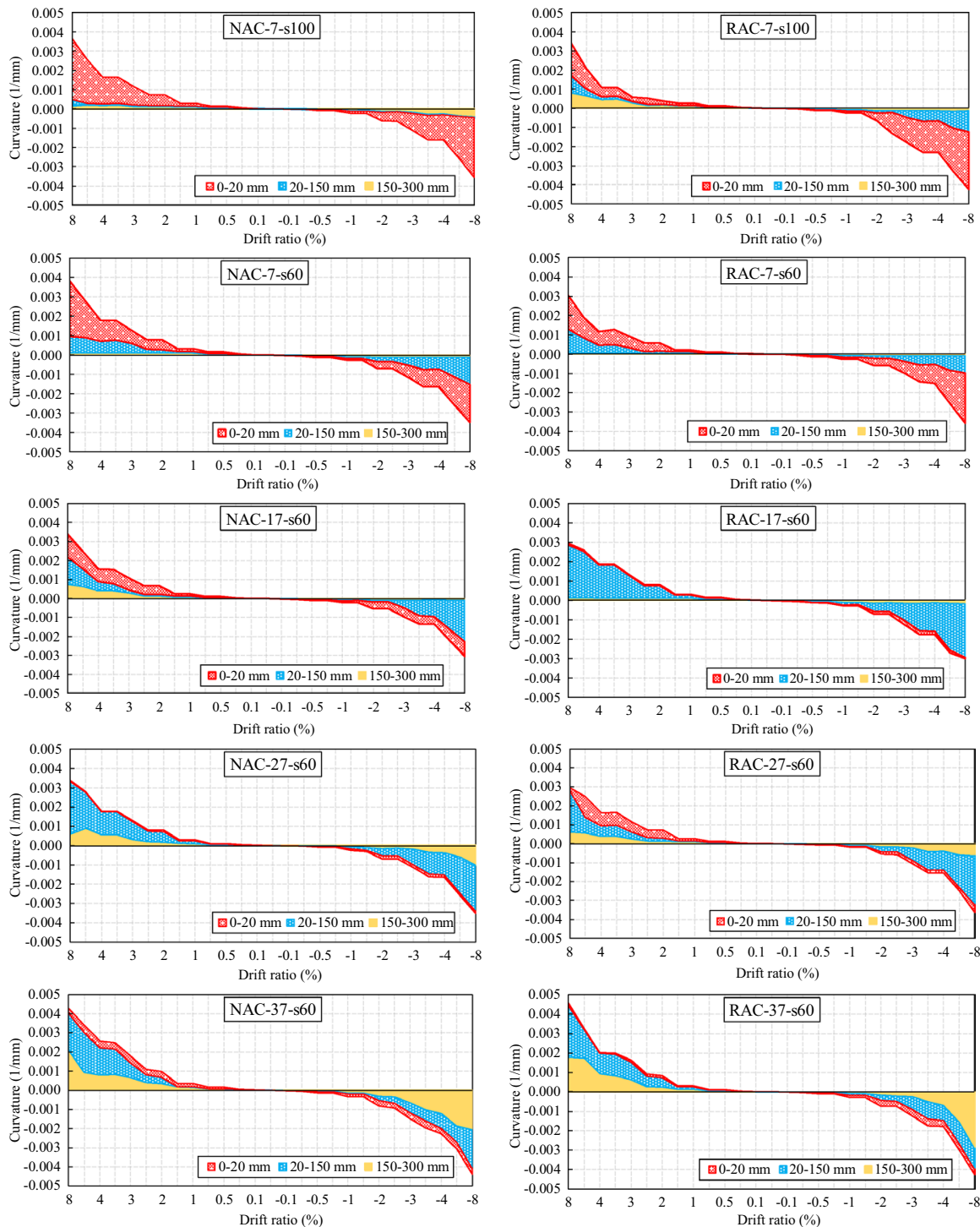

Fig. 13 Curvature-drift ratio relationships obtained in different gage lengths 